Check for updates

Cite this: RSC Adv., 2018, 8, 3041

Received 6th October 2017

Accepted 8th January 2018

DOI: $10.1039 / c 7 r a 10994 f$

rsc.li/rsc-advances

\title{
Effects of heavy metals on health risk and characteristic in surrounding atmosphere of tire manufacturing plant, Taiwan
}

\author{
Chia-Hsiang Lai, (D) *a Chia-Hua Lin, (D) ${ }^{\mathrm{b}}$ Chang-Chun Liao, ${ }^{\mathrm{c}}$ Kuen-Yuan Chuang ${ }^{\mathrm{d}}$ \\ and Yen-Ping Peng ${ }^{\mathrm{e}}$
}

The health and environmental effects of metal-containing carbon black (CB) particles emitted from a CB feeding area near a tire manufacturing plant were investigated. The mass ratios of $\mathrm{PM}_{1}$ and $\mathrm{PM}_{0.1}$ (UFPs) relative to TSP were $13.84 \% \pm 4.88 \%$ and $50.84 \% \pm 4.29 \%$, respectively. The most abundant elements in all fractions were $\mathrm{Fe}, \mathrm{Al}$, and $\mathrm{Zn}$. The mean percentage contributions of $\mathrm{Al}, \mathrm{Fe}, \mathrm{Zn}, \mathrm{Cu}$, and $\mathrm{Co}$ to the coarse particles ranged from $49.1 \%$ to $69.1 \%$, thus indicating that the $\mathrm{Al}, \mathrm{Fe}$, and $\mathrm{Zn}$ contents in the CB particles were affected by workplace emissions. The ratios of the total mean deposition fluxes of atmospheric particle-bound heavy metals in the human respiratory tracts of workers/adults, workers/ children, and adults/children were approximately 5.5, 11.0, and 2.0, respectively. The integrated risks of five elements via two exposure pathways to adults and children were $1.1 \times 10^{-4}$ and $1.7 \times 10^{-5}$, respectively; these numbers reflect the high cumulative carcinogenic risk posed by these toxic metals to local residents (both adults and children; limit, $10^{-6}$ ). These results demonstrate the potential health risk presented by particle-bound heavy metals to humans residing near tire manufacturing plants via inhalation and dermal contact exposure.

\section{Introduction}

Carbon black (CB) is a manufactured product consisting of a fine powder of pure elemental carbon, organic compounds, and inorganics. ${ }^{1-3} \mathrm{CB}$ is widely used in a number of common consumer products and industrial manufacturing (e.g., rubber, ink, printing, paint, paper, plastics, ceramics, batteries, carbon electrode products, and tires) and has been studied intensively by health scientists in recent decades. Several studies focusing on $\mathrm{CB}$ exposure have addressed $\mathrm{CB}$ manufacturing and its production, collection, and handling. ${ }^{4-7}$ While epidemiological studies among workers in $\mathrm{CB}$ production and the rubber industry have provided inadequate evidence of carcinogenicity, overall data from cancer studies in rodents exposed to $\mathrm{CB}$ have gathered sufficient evidence of carcinogenicity. In fact, the Working Group has evaluated $\mathrm{CB}$ as a possible Group 2B carcinogen to humans. ${ }^{4}$

\footnotetext{
${ }^{a}$ Department of Safety Health and Environmental Engineering, Central Taiwan University of Science and Technology, Taichung, Taiwan. E-mail: chlai2@ctust.edu. tw; Tel: $+8864-22391647$

${ }^{b}$ Department of Biotechnology, National Formosa University, Yunlin, 63208, Taiwan 'Institute of Safety Health and Environmental Engineering, Central Taiwan University of Science and Technology, Taichung, Taiwan

${ }^{d}$ Department of Safety Health and Environmental Engineering, Central Taiwan University of Science and Technology, Taichung, Taiwan

${ }^{e}$ Department of Environmental Science and Engineering, Tung Hai University, Taichung, Taiwan
}

CB is poorly soluble and nano-sized. ${ }^{4}$ The increased biological potency of ultrafine particles is related to the content of redox cycling organic chemicals and their ability to damage mitochondria. ${ }^{8}$ Besides increasing reactive oxygen species, nano-sized CB causes loss of cell viability in endothelial cells and promotes adhesion of monocytes, both of which accelerate the development of atherosclerosis. ${ }^{9} \mathrm{CB}$ aggregates cause endothelial dysfunction by activating ROCK. ${ }^{\mathbf{1 0}, 11}$ Moreover, trace elements $(\mathrm{Ca}, \mathrm{Cu}, \mathrm{Fe}, \mathrm{Mn}, \mathrm{K}, \mathrm{Pb}, \mathrm{As}, \mathrm{Cr}, \mathrm{Se}$, and $\mathrm{Zn})$ have been found in samples of $\mathrm{CB} \cdot{ }^{12} \mathrm{Cd}, \mathrm{Cr}$ and $\mathrm{Pb}$ are known to cause deleterious effects on human health. ${ }^{13}$ Arsenic (As) can cause serious disturbances of cardiovascular and central nervous system..$^{14}$ Long-term exposure to $\mathrm{Pb}$ may lead to memory deterioration, prolonged reaction times and reduced ability to understand. Dietary $\mathrm{Cr}$ intakes were assumed to be directly correlated with breast cancer mortalities. ${ }^{15}$ Although CB is known to typically contain large quantities of elemental carbon and PAHs, some toxic components of the material, e.g., metals, are not widely discussed. CB is emitted during industrial manufacturing, and the particles are deposited in the human respiratory tract by breathing and exposure to polluted environments. As the specific effects of the size distributions of metal-containing CB particles on workers and residents in tire manufacturing plants and the surrounding areas are not known, analyzing the hazards and risks of exposure to different sizes of metal-containing particles is an important and novel research topic. 
The objective of this study is to collect and analyze sizesegregated suspended particle samples for the presence of heavy metals. Respiration and dermal contact are regarded as significant intake pathways of human exposure to heavy metals. The CB feeding and surrounding areas of a tire manufacturing plant were selected as sampling sites, and the size distributions of heavy metals were characterized and used to estimate deposition fluxes in the human respiratory system via a model developed by the International Commission on Radiological Protection (ICRP). Finally, the carcinogenic effects of exposure to heavy metal-containing particles through inhalation and dermal contact were evaluated.

\section{Methodology}

\section{Sampling site and sample collection}

In Taiwan, many factories were built near the farmlands in the rural county more than 30 years ago. With the rapid development of rural economy and population, the adverse effects of pollutants on health and environment from the emitting sources raised severe public concern. The tire manufacturing plant was located in a rural county in Central Taiwan. Although several farmlands, irrigation ditches, and residential areas are present around this tire plant, no large industrial area is present. This study analyzed the ambient atmosphere of the CB feeding and surrounding areas at the tire manufacturing plant. Details of the tire production processes in the plant were described in our previous study. ${ }^{\mathbf{1 6}}$ Four grades of CB products (i.e., $\mathrm{N}-220, \mathrm{~N}-330, \mathrm{~N}-339$, and $\mathrm{N}-660$ ) are used in different tire products (e.g., truck tires and vehicle tires).

In this study, the sampled particles were collected from the feeding and surrounding area simultaneously during the feeding process. Atmospheric particles were collected at two sampling sites for 20 days in March and April 2016 using a 12stage micro-orifice uniform deposit impactor (MOUDI II, model M110-R). Sampling was carried out at a flow rate of $30 \mathrm{~L} \mathrm{~min}^{-1}$ and air particulate samples of different size fractions were collected from each sampling site over $24 \mathrm{~h}$. Four hundred and eighty air samples were collected. The Central Taiwan's weather station located at approximately $1.5 \mathrm{~km}$ toward north-northwest (NNW) of the sampling site provides meteorological parameters including pressure, temperature, wind speed, wind direction, and relative humidity $(\mathrm{RH})$. The mean pressure was $1012.44 \pm 2.57(\mathrm{hPa})$, mean temperature was $22.34 \pm 3.40{ }^{\circ} \mathrm{C}$, mean $\mathrm{RH}$ was $83.62 \pm 7.31 \%$, and prevailing wind direction was northwest (NW) during the sampling periods. The sampling site was located downwind of CB-emitting source in surrounding area. The $50 \%$ cut off diameters $\left(D_{50}\right)$ of the MOUDI stages were $10.0,5.6,3.2,1.8,1.0,0.56,0.32,0.18,0.10$, and $0.056 \mu \mathrm{m}$ and included inlet $(18 \mu \mathrm{m})$ and exit $(<0.056 \mu \mathrm{m})$ stages. Sizesegregated particles were classified as coarse (aerodynamic diameter $>1.8 \mu \mathrm{m}$ ) and ultrafine (aerodynamic diameter < $0.1 \mu \mathrm{m})$. The distance between the sampling site and the CB feeding area was approximately $2 \mathrm{~m}$. Another sampling site representing the surrounding area was located near a fence about $15 \mathrm{~m}$ from the factory building. Several farmlands and irrigation rivers of agricultural land are affected by CB

\section{Sample preparation}

1. Calibrate the flow rate of MOUDI equipment.

2. Perform the conditioning of MCE filters by equilibrating them in a dust-free desiccator $(\mathrm{RH}=$ $40 \% \pm 5 \%$, temperature $=25^{\circ} \mathrm{C} \pm 2{ }^{\circ} \mathrm{C}$ ) for $24 \mathrm{~h}$.

\section{Sample collection}

1. Install the MOUDI equipment.

2. Collect samples from the CB feeding and surrounding areas simultaneously for $24 \mathrm{~h}$.

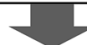

\section{Sample analysis}

1. Perform the microwave digestion of filters using $\mathrm{HNO}_{3}$ and deionized water.

2. Filter the digested solution, and perform the dilution procedures.

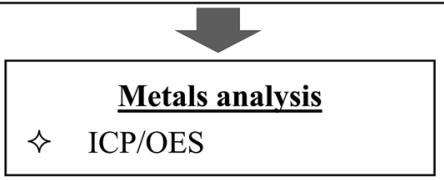

Fig. 1 Flowchart for sampling and analysis of samples.

emissions near the tire manufacturing plant. The inlet of the MOUDI sampler place in the CB feeding area was set $1.5 \mathrm{~m}$ high from the ground. Ambient air samples of the surrounding area were also collected from the roof of a building located near the factory fence at a height of about $3 \mathrm{~m}$ above ground level. A total of 240 particle samples (20 samples containing 12 size fractions) were collected from every sampling site. Mixed cellulose ester (MCE) membrane filters (Advantec MFS Inc., $47 \mathrm{~mm}$ diameter, $0.45 \mu \mathrm{m}$ pore size) were used as the substrate in all stages of collection the MOUDI sampler. Both blank and loaded MCE substrates were conditioned for $24 \mathrm{~h}$ by maintaining a humidity of $40 \% \pm 5 \%$ and temperature of $25 \pm 2{ }^{\circ} \mathrm{C}$ to equilibrate before and after each sampling. A laboratory standard weight of $10 \mathrm{mg}$ was measured before, during, and after each weighing session to ensure accuracy of the weight measurements. Each filter was weighed on an electrical balance with a sensitivity of $10 \mu \mathrm{g}$, and the suspended particulate matter (PM) concentration was determined by dividing the particle mass by the volume of the sampled air. Fig. 1 shows a flowchart of the sampling and analysis procedures.

\section{Instrumental analysis and quality control}

The concentrations of metal elements (Al, Cd, Co, Cr, Cu, Fe, $\mathrm{Ga}$, In, $\mathrm{Mn}, \mathrm{Ni}, \mathrm{Pb}, \mathrm{Sr}$, and $\mathrm{Zn}$ ) were analyzed by inductively coupled plasma-optical emission spectrometry (ICP-OES) (PerkinElmer Optima 8000 device). All samples collected by the MOUDI instrument were analyzed according to Method 7302 of the National Institute for Occupational Safety and Health. The loaded filters were then digested in $\mathrm{HNO}_{3}$ via a microwave 
digestion system (Model: ETHOS One; Milestone Inc.) as follows:

Step 1: Each filter was placed in a $100 \mathrm{~mL}$ Teflon microwave digestion vessel with $10 \mathrm{~mL}$ of a mixture of concentrated $\mathrm{HNO}_{3}$ (70\%, trace metal grade) and de-ionized water at a volume ratio of $1: 1$ in preparation for microwave digestion.

Step 2: The microwave temperature was increased from room temperature to $200{ }^{\circ} \mathrm{C}$ over $6.5 \mathrm{~min}$.

Step 3: The temperature was maintained at $200{ }^{\circ} \mathrm{C}$ for another $10 \mathrm{~min}$.

Step 4: The samples were cooled for $20 \mathrm{~min}$, and the digested solution was diluted to $20 \mathrm{~mL}$ using $20 \% \mathrm{HNO}_{3}$ in de-ionized water. The resulting diluted solution was used for metal analysis.

Calibration was performed using multi-element (metal) standards (i.e., certified reference materials) in a $20 \%(\mathrm{v} / \mathrm{v}) \mathrm{HNO}_{3}$ solution. The detection limit of the ICP-OES instrument for the 13 metals was $0.91-3.52 \mathrm{ng} \mathrm{m}^{-3}$. Field and laboratory blank samples were subjected to the same analytical procedure as the samples that were regularly analyzed, and sample data were corrected by subtraction of the filter blanks. This study measured recoveries with one medium blank and two spiked medium blanks per 20 samples. Recovery efficiencies were determined by performing the same experimental procedures using solutions containing known metal concentrations as samples. The recovery values of the metals ranged from $91.1 \%$ to $98.5 \%$.

\section{Deposition fraction and health-risk assessment}

To estimate the deposition efficiency and flux of inhaled particles in the human respiratory tract, this study adopted the simplified equations from the ICRP (1994) model. ${ }^{17}$ The model calculates size-resolved metals deposition in three main regions of the human respiratory tract, i.e., (1) head airway (HA), (2) tracheobronchial region (TB), and (3) alveolar region (AR). The deposition efficiencies of size-specific particles in the $\mathrm{HA}\left(\mathrm{DF}_{\mathrm{HA}_{i}}\right), \mathrm{TB}\left(\mathrm{DF}_{\mathrm{TB}_{i}}\right)$, and $\mathrm{AR}\left(\mathrm{DF}_{\mathrm{AR}_{j}}\right)$ can be estimated by the following equations:

$$
\begin{aligned}
\mathrm{DF}_{\mathrm{HA}}= & \mathrm{IF}_{i} \times\left[\frac{1}{1+\exp \left(6.48+1.183 \ln D_{\mathrm{p}_{i}}\right)}\right. \\
& \left.+\frac{1}{1+\exp \left(0.924-1.885 \ln D_{\mathrm{p}_{i}}\right)}\right] \\
\mathrm{IF}= & 1-0.5\left(1-\frac{1}{1+0.00076 D_{\mathrm{p}_{i}}{ }^{2.8}}\right) \\
\mathrm{DF}_{\mathrm{TB}}= & \frac{0.00352}{D p_{i}} \times\left[\exp \left(0.234\left(\ln D_{\mathrm{p}_{i}}+3.40\right)^{2}\right)\right. \\
& \left.+63.9 \exp \left(-0.819\left(\ln D_{\mathrm{p}_{i}}-1.61\right)^{2}\right)\right] \\
\mathrm{DF}_{\mathrm{AR}}= & \frac{0.0155}{D_{\mathrm{p}_{i}}} \times\left[\exp \left(-0.416\left(\ln D_{\mathrm{p}_{i}}+2.84\right)^{2}\right)\right. \\
& \left.+19.11 \exp \left(-0.482\left(\ln D_{\mathrm{p}_{i}}-1.362\right)^{2}\right)\right] \\
& \mathrm{DF}_{\mathrm{T}}=\sum\left(\mathrm{DF}{ }_{i} \times C_{i}\right) \times V
\end{aligned}
$$

where $D_{\mathrm{p}_{i}}(\mu \mathrm{m})$ is the geometric mean diameter (GMD) of each size-segregated particle class (here, the GMD of size fraction $>18 \mu \mathrm{m}$ is defined as $20 \mu \mathrm{m}$ (ref. 18)) and IF is the inhalable fraction of all particles; $\mathrm{DF}_{\mathrm{T}}$ is the total deposition flux from inhalation (ng per day). The sum of the deposition efficiencies in all three regions was defined as the total deposition efficiency.

The health risk presented by metal inhalation to persons working in the CB feeding area was evaluated by quantifying the risk of developing cancer using a probabilistic approach. This study adopted the inhalation exposure model of the United States Environmental Protection Agency (US-EPA) baseline risk assessment approach. ${ }^{19}$ The EPA Integrated Risk Information Database and International Agency for Research on Cancer classify pollutants as carcinogens. This investigation found that $\mathrm{Cr}, \mathrm{Ni}, \mathrm{Cd}$, and As are carcinogenic and could affect the human immune system through the respiratory system. The average daily exposure dose of metallic particles through inhalation $\left(\mathrm{ADD}_{\mathrm{inh}}\right)$ and dermal contact $\left(\mathrm{ADD}_{\mathrm{derm}}\right)$ were calculated using the following equations: ${ }^{16,20}$

$$
\begin{gathered}
\mathrm{ADD}_{\text {inh }}=\frac{V C_{i} f_{\mathrm{r}}\left(\frac{T}{24}\right) \mathrm{EF} \times \mathrm{ED} \times \mathrm{ADAF}}{\mathrm{BW} \times \mathrm{AT}} \\
\mathrm{ADD}_{\text {derm }}=\frac{C_{\mathrm{d}} \times \mathrm{SAF} \times A_{\text {skin }} \times \mathrm{DAF}\left(\frac{T}{24}\right) \mathrm{EF} \times \mathrm{ED}}{\mathrm{BW} \times \mathrm{AT}} \times \mathrm{CF}
\end{gathered}
$$

Cancer risk (CR) estimates were compared with carcinogenic regulatory levels of concern, i.e., $10^{-6}$ to $10^{-4}$. Health risk can be quantified using the following equation:

$$
\mathrm{CR}=\mathrm{ADD} \times \mathrm{SF}
$$

where ADD denotes the life-averaged daily dose from inhalation and dermal contact (mg per day per $\mathrm{kg}$ ); $C_{i}$ denotes the air concentration of a metal ( $\left.\mathrm{ng} \mathrm{m}^{-3}\right)$, including the total concentration in all size fractions; $C_{\mathrm{d}}$ denotes the contact skin concentration of a metal $\left(\mathrm{mg} \mathrm{kg}^{-1}\right)$, including the total concentration in all size fractions; $f_{\mathrm{r}}$ is the deposition efficiency of particles in each region; $V$ is the inhalation rate of humans, which was assumed to be $20 \mathrm{~m}^{3}$ per day; $T$ is the time spent at the impact site per day (approximately $8 \mathrm{~h}$ for workers and $24 \mathrm{~h}$ for residents); $A_{\text {skin }}$ is the skin surface area $\left(5700 \mathrm{~cm}^{2}\right.$ for adults and $2800 \mathrm{~cm}^{2}$ for children); ${ }^{19}$ ADAF is defined as an agedependent adjustment factor (adult: 1 ; children: 3 ); ${ }^{21,22} \mathrm{SAF}$ is the skin adherence factor $\left(0.7 \mathrm{mg} \mathrm{cm}{ }^{-2}\right.$ per day for adult and $0.2 \mathrm{mg} \mathrm{cm}{ }^{-2}$ per day for children); ${ }^{19}$ DAF is dermal absorption factor (0.001); ${ }^{23} \mathrm{EF}$ is the number of days spent at the impact site annually (equal to 260 days for workers and 365 days for residents); ED is the number of years spent at the impact site in a lifetime (equal to 30 years for workers, 24 years for adult residents, and 6 years for children); BW is the body weight of an adult $(70 \mathrm{~kg})$; AT is the average time $(70 \times 365$ days $)$; $\mathrm{CF}$ is a conversion factor $\left(10^{-6} \mathrm{~kg} \mathrm{mg}^{-1}\right)$; CR is the cancer risk due to metal exposure over an expected lifetime of 70 years; and SF is the cancer slope factor $\left(\mathrm{kg}\right.$ day $\left.\mathrm{mg}^{-1}\right)$. 
Table 1 Concentrations (mean $\pm \mathrm{SD}$ ) of particulate matter of various sizes (unit: $\mu \mathrm{g} \mathrm{m}^{-3}$ ) in the ambient air of the carbon black feeding and surrounding areas of a tire manufacturing

\begin{tabular}{lcc}
\hline $\begin{array}{l}\text { Aerodynamic diameter } \\
(\mu \mathrm{m})\end{array}$ & Surrounding area & CB feeding workplace \\
\hline$>18$ & $8.29 \pm 4.92$ & $250.33 \pm 170.02$ \\
$10-18$ & $7.77 \pm 4.49$ & $72.18 \pm 36.65$ \\
$5.6-10$ & $8.72 \pm 4.61$ & $184.27 \pm 108.56$ \\
$3.2-5.6$ & $9.48 \pm 4.96$ & $166.85 \pm 70.80$ \\
$1.8-3.2$ & $8.91 \pm 4.18$ & $83.53 \pm 36.62$ \\
$1.0-1.8$ & $9.49 \pm 4.86$ & $49.49 \pm 19.08$ \\
$0.56-1.0$ & $14.20 \pm 9.11$ & $44.26 \pm 24.36$ \\
$0.32-0.56$ & $9.64 \pm 5.23$ & $24.43 \pm 8.88$ \\
$0.18-0.32$ & $9.25 \pm 4.06$ & $27.08 \pm 9.83$ \\
$0.1-0.18$ & $7.17 \pm 3.93$ & $23.34 \pm 8.03$ \\
$0.056-0.1$ & $6.28 \pm 3.46$ & $9.70 \pm 5.84$ \\
$<0.056$ & $8.47 \pm 5.45$ & $9.31 \pm 3.59$ \\
Total & $107.66 \pm 54.43$ & $944.76 \pm 456.36$ \\
\hline PM $_{10}\left(\mathrm{PM}_{10} / \mathrm{TSP}\right)$ & $91.59 \pm 45.66$ & $622.24 \pm 268.49$ \\
& $(85.36 \pm 2.48 \%)$ & $(68.10 \pm 7.60 \%)$ \\
PM $_{1}\left(\mathrm{PM}_{1} / \mathrm{TSP}\right)$ & $54.99 \pm 28.06$ & $138.11 \pm 53.33$ \\
& $(50.84 \pm 4.29 \%)$ & $(16.91 \pm 7.45 \%)$ \\
$\mathrm{UFPs}_{(\mathrm{UFPs} / \mathrm{TSP})}$ & $14.74 \pm 8.01$ & $19.01 \pm 7.02$ \\
& $(13.84 \pm 4.88 \%)$ & $(2.67 \pm 1.92 \%)$ \\
MMD $(\mu \mathrm{m})$ & $0.56 \pm 0.11$ & $2.28 \pm 0.61$ \\
& & \\
& &
\end{tabular}

\section{Results and discussion}

\section{Mass of particulate matter}

Table 1 shows the mass concentrations of atmospheric PM of different particle sizes in the tire manufacturing plant. The concentrations of total PM in the surrounding and CB feeding areas were $107.66 \pm 54.43$ and $944.8 \pm 456.4 \mu \mathrm{g} \mathrm{m}^{-3}$, respectively. The mass concentrations in the feeding area were approximately 8.8 times higher than those in the surrounding area. In the surrounding area, particles with the highest mass by size included $\mathrm{PM}_{0.56-1.0}\left(14.20 \pm 9.11 \mu \mathrm{g} \mathrm{m}^{-3}\right)$, followed by $\mathrm{PM}_{0.32-0.56}$ $\left(9.64 \pm 5.23 \mu \mathrm{g} \mathrm{m} \mathrm{m}^{-3}\right)$ and $\mathrm{PM}_{1.0-1.8}\left(9.49 \pm 4.86 \mu \mathrm{g} \mathrm{m} \mathrm{m}^{-3}\right)$. The mass ratios of $\mathrm{PM}_{0.1}$ (UFPs) and $\mathrm{PM}_{1}$ relative to TSP were $13.84 \% \pm 4.88 \%$ and $50.84 \% \pm 4.29 \%$, respectively. Overall, the mass ratios of $\mathrm{PM}_{10}$ relative to TSP ranged from $80.66 \%$ to $89.11 \%$ with an average of $85.36 \% \pm 2.48 \%$.

Differences in particle mass and size distributions between the surrounding and CB feeding areas were compared. Table 1 shows that the UFPs/TSP and $\mathrm{PM}_{1} /$ TSP ratios in the CB feeding area were $2.67 \% \pm 1.92 \%$ and $16.91 \% \pm 7.45 \%$, respectively. The mass ratio of particles sized below $1 \mu \mathrm{m}$ in the CB feeding area was significantly less than that in the surrounding area. However, the $\mathrm{PM}_{1}$ mass was distributed over more than $50 \%$ of the surrounding area, which suggests that the total mass of airborne particles is still incorporated with the submicron particles in this study.

\section{Distribution of metallic elements in different-size particles}

Table 2 shows the mean concentrations of metallic elements collected from the atmosphere of the surrounding and CB feeding areas. The mean concentrations of total metals of all particle sizes were $1034.3 \pm 355.8$ and $13999.6 \pm 8362.4 \mathrm{ng} \mathrm{m}^{-3}$, respectively. The concentrations of total metals in the CB feeding area were approximately $\mathbf{1 3 . 5}$ times higher than those in the surrounding area. The most abundant elements in all fractions obtained from the CB feeding area were $\mathrm{Zn}\left(8622.0 \pm 5679.0 \mathrm{ng} \mathrm{m}^{-3}\right), \mathrm{Al}$ $\left(3113.3 \pm 2017.1 \mathrm{ng} \mathrm{m}^{-3}\right)$, and Fe $\left(1519.1 \pm 875.0 \mathrm{ng} \mathrm{m}^{-3}\right) . \mathrm{Zn}$ particles made up the highest proportion $(57.3 \% \pm 10.4 \%)$ of metals relative to the total metal concentration at all particle sizes. ZnO powder is used as an activator during the tire manufacturing process; ${ }^{24}$ it also adds strength to rubber compounds, improves their resistance to heat and abrasion, and helps guard against ultraviolet degradation.

The most abundant elements (Fe, $\mathrm{Al}$, and $\mathrm{Zn}$ ) in all fractions in the surrounding area were similar to those in the CB feeding area. The abundance of these three metal elements is believed to be influenced by $\mathrm{CB}$ feeding emissions. Fe, not $\mathrm{Zn}$, was the most abundant metal relative to the total metal concentration

Table 2 Mean concentrations and weight percentages of particle-bound heavy metals in the carbon black feeding and surrounding areas

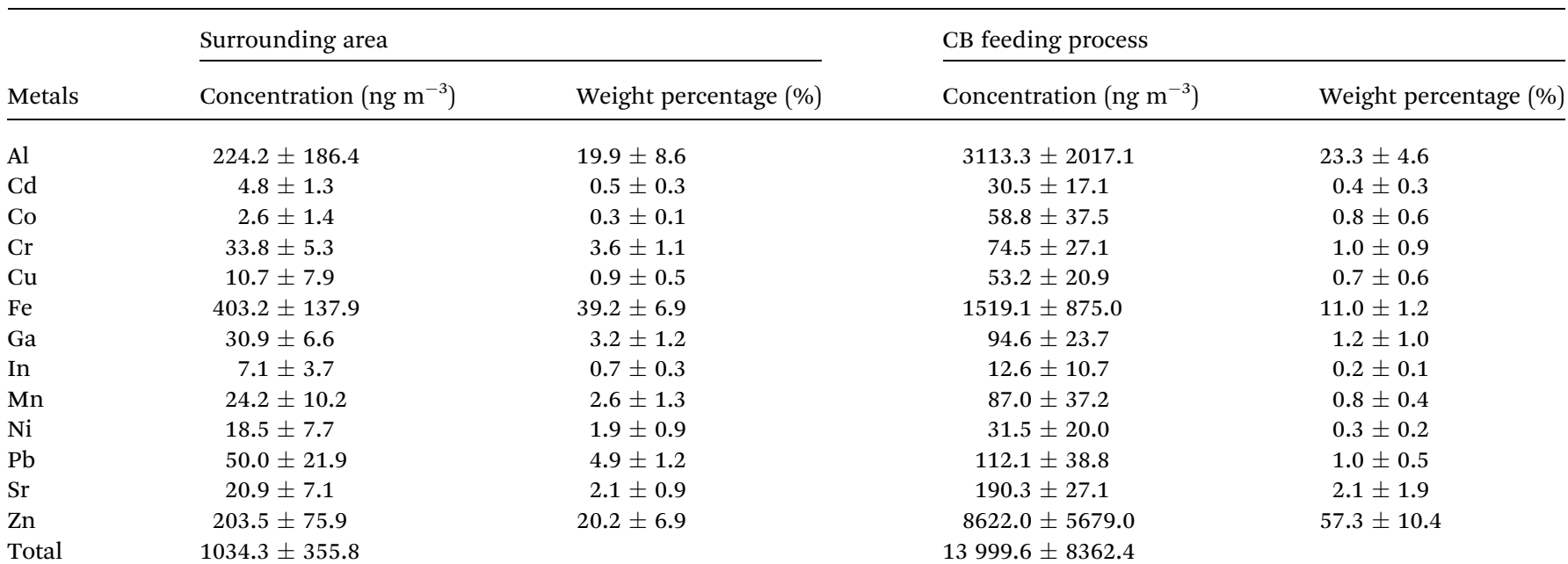


Table 3 Correlation of heavy metal concentrations in UFPs in the surrounding area ${ }^{a}$

(a) Spearman correlation

\begin{tabular}{|c|c|c|c|c|c|c|c|c|c|c|c|c|c|}
\hline $\mathrm{Al}$ & 1 & & & & & & & & & & & & \\
\hline $\mathrm{Fe}$ & $0.82^{* *}$ & 1 & & & & & & & & & & & \\
\hline $\mathrm{Sr}$ & & & & 1.00 & & & & & & & & & \\
\hline $\mathrm{Cu}$ & $0.87^{* *}$ & $0.94 * *$ & & & 1.00 & & & & & & & & \\
\hline $\mathrm{Mn}$ & & & & & & 1.00 & & & & & & & \\
\hline $\mathrm{Cd}$ & & & & $0.63 *$ & & & $0.68 *$ & & 1.00 & & & & \\
\hline Co & & & & & & & $0.71 *$ & & $0.79 * *$ & 1.00 & & & \\
\hline $\mathrm{Cr}$ & & & & & & & $0.62 *$ & & & & 1.00 & & \\
\hline $\mathrm{Ga}$ & & & & $0.61^{*}$ & & & $0.65^{*}$ & & & & $0.64^{*}$ & 1.00 & \\
\hline In & & & 0.85 & & & & & 0.70 & & & & & 1 \\
\hline
\end{tabular}

(b) Particle correlation: control variable (Al)

\begin{tabular}{lcc}
\hline & $\mathrm{Fe}$ & $\mathrm{Pb}$ \\
\hline $\mathrm{Fe}$ & 1 & $\mathrm{Cu}$ \\
$\mathrm{Pb}$ & -0.43 & 1 \\
$\mathrm{Cu}$ & $0.81^{* *}$ & -0.24 \\
$a *$ significant level $(p<0.05$, two-tailed $) ; * *$ significant level $(p<0.01$, two-tailed $)$. & \\
\hline
\end{tabular}

in the surrounding area. Individual metal elements are affected to an appreciable extent by other pollution sources. Heavy-duty diesel vehicles and forklift trucks are operated near the tire factory fence, causing increases in Fe concentration in the surrounding area. Previous studies have indicated that Fe could be emitted by both exhaust (diesel emissions) ${ }^{25,26}$ and nonexhaust (brake wear and road dust) ${ }^{24,27}$ traffic sources. Diesel exhaust is the most important traffic-related nanoparticle source. ${ }^{28}$ Table $3(\mathrm{a})$ indicates that $\mathrm{Al}, \mathrm{Cu}, \mathrm{Fe}$, and $\mathrm{Pb}$ are the most abundant metallic elements in UFPs in the surrounding area. These metals ( $\mathrm{Al}, \mathrm{Cu}$, and $\mathrm{Fe}$ ) are mainly associated with

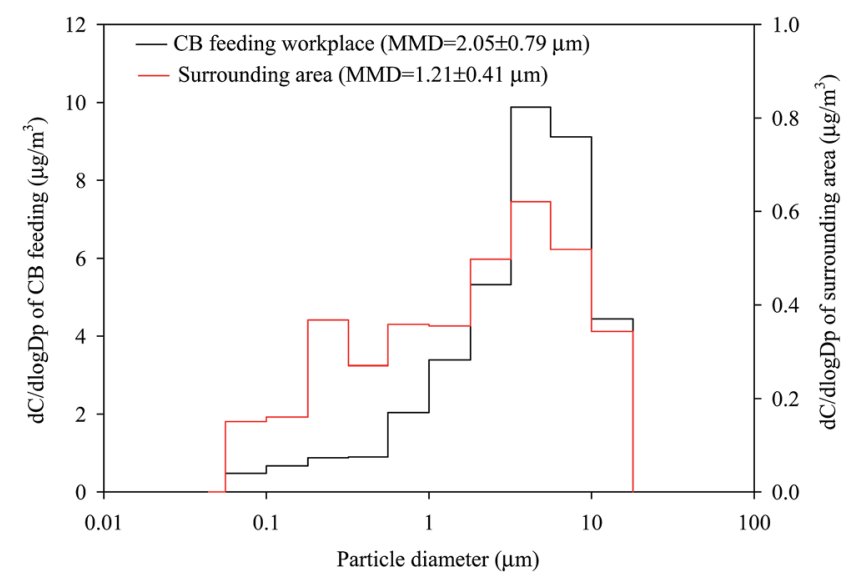

Fig. 2 Size distributions of total particle-bound heavy metals in the ambient air of the CB feeding and surrounding areas. (a) CB feeding workplace. (b) Surrounding area. diesel sources. ${ }^{25,26}$ To obtain further information of the main $\mathrm{Pb}$ source in the surrounding area, we applied partial correlation to measure the degree of association between two random variables $(\mathrm{Fe}, \mathrm{Pb}$, and $\mathrm{Cu}$ ) with the effect of a set of controlling random variables removed $(\mathrm{Al})$; the results of this analysis are shown in Table 3(b). Analysis indicated that $\mathrm{Fe}$ and $\mathrm{Cu}$ were highly correlated with each other $(0.81, p<0.05)$ and that $\mathrm{Pb}$ was lowly negatively correlated with $\mathrm{Fe}$ and $\mathrm{Cu}(-0.43$ and -0.24 , respectively; $p>0.05)$. These results reveal that $\mathrm{Pb}$ in UFPs is not likely emitted by CB feeding or traffic sources. By contrast, other metals (e.g., $\mathrm{Al}, \mathrm{Fe}$, and $\mathrm{Zn}$ ) in UFPs in the surrounding area could be associated with tire manufacturing plant emissions.

Fig. 2 shows the mean normalized size distributions of total metal concentrations in the atmosphere of the CB feeding and surrounding areas; a unimodal distribution located at 5.6-10 $\mu \mathrm{m}$ was observed at the two sites. The mass median diameter (MMD) of the total metal concentrations in the surrounding and CB feeding areas were $1.21 \pm 0.41 \mu \mathrm{m}$ and $2.05 \pm 0.79 \mu \mathrm{m}$, respectively, which suggests that the airborne total metals in these sites were incorporated in submicron and fine particles, respectively. Fig. 3 shows the mean normalized size distributions of individual metal concentrations in surrounding areas. Fig. 3(a) and (b) show that $\mathrm{Al}, \mathrm{Mn}$, and $\mathrm{Cu}$ have a unimodal distribution, exhibiting a major peak at 3.2, 0.18, and $5.6 \mu \mathrm{m}$, respectively. Fig. 3(a) shows that $\mathrm{Al}$ and $\mathrm{Fe}$, exhibiting a major peak at $3.2 \mu \mathrm{m}$, are the most abundant metals in the surrounding area. On the contrary, Fig. 3(c) shows that the other metals do not have significant variances in particle-size distributions in the surrounding area. Although the exposure hazard of submicron- 

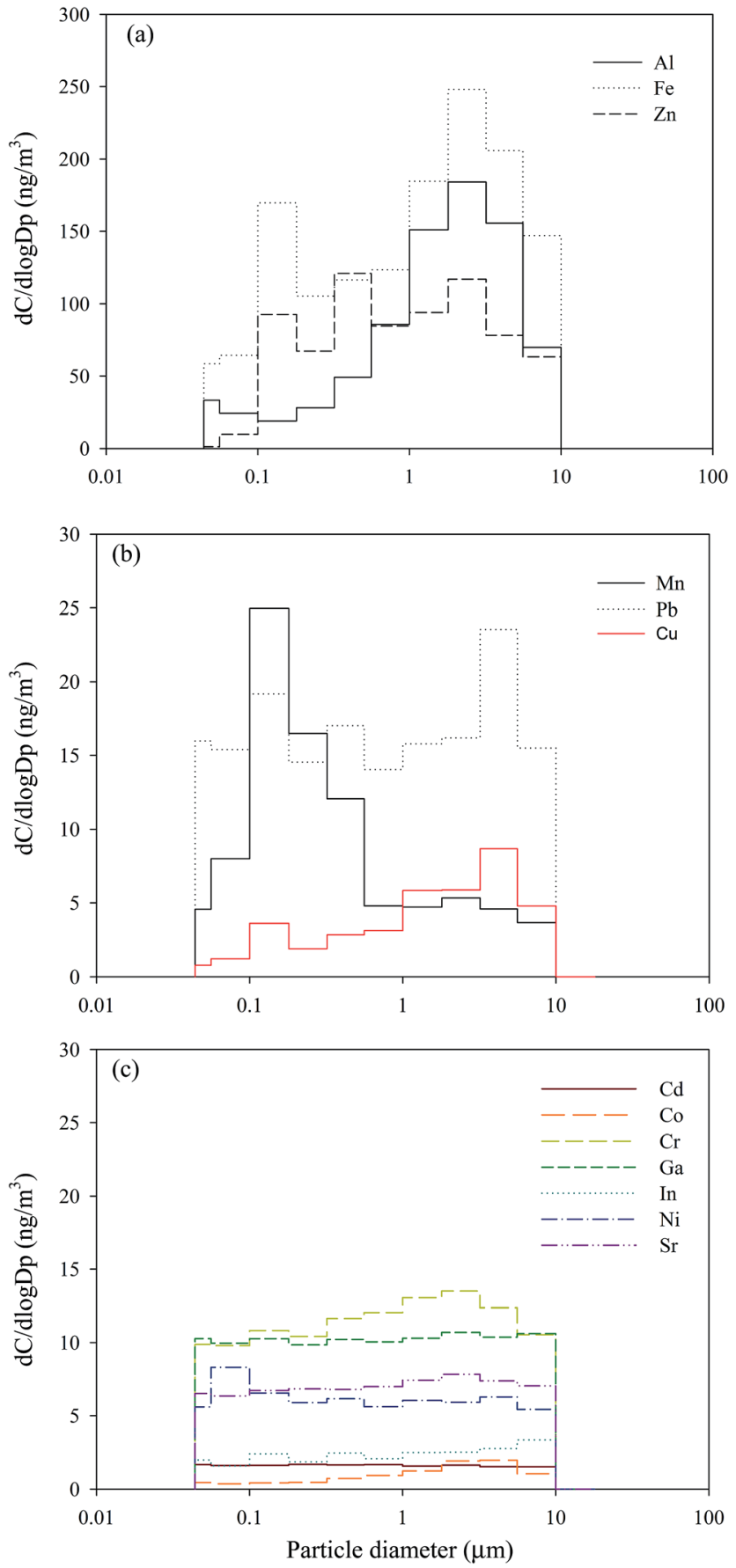

Fig. 3 Size distributions of individual particle-bound heavy metals in the ambient air of surrounding areas.

sized particles for residents was higher than that of fine particles for workers, long-term inhalation of high toxic metal levels in the CB feeding area may lead to adverse health effects among workers. Assessment of the CR presented by carcinogenic metals is discussed later in this study.

\section{Comparison of the sources and contents of heavy metals}

While correlation analysis can illustrate that two metals come from the same source, it cannot group these sources accordingly. We applied cluster analysis to identify differences in (a) CB feeding workplace

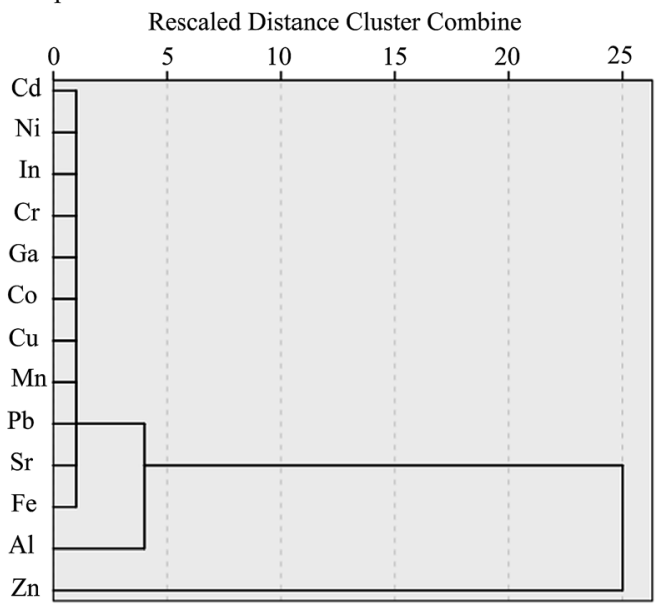

(b) Surrounding area

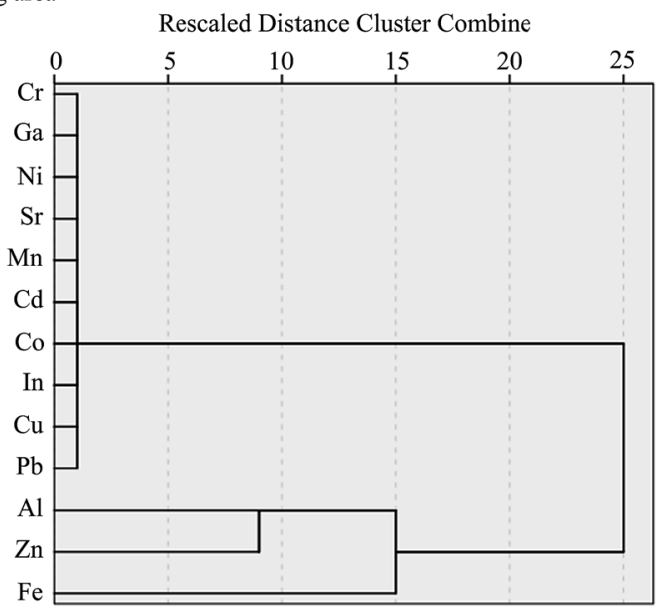

Fig. 4 Dendrogram results of the Ward method of hierarchical cluster analysis of 13 elements in the (a) CB feeding and (b) surrounding areas.

emission sources by clustering samples (13 metals in all size particles) with similar heavy metal contents between the CB feeding and surrounding areas. Cluster analysis is used for exploratory data mining and can group a set of objects into more mutually exclusive unknown groups based on a combination of internal variables. Most research uses hierarchical clustering according to Ward's method to achieve this goal. ${ }^{29-31}$ Fig. 4 shows the dendrogram results of hierarchical cluster analysis of 13 metals in all particle sizes in the CB feeding and surrounding areas. Prior to cluster analysis, the variables were standardized by means of $z$-scores; thereafter, the Euclidean distances of similarities in the variables were calculated. Fig. 4(a) presents two large subgroups in the CB feeding area: the first group contains only the variable $\mathrm{Zn}$ while the second one includes $\mathrm{Al}$ and other metals. The $\mathrm{Zn}$ in the first group is mainly obtained from the addition of $\mathrm{ZnO}$ powder in the $\mathrm{CB}$ feeding process, and the metals in the second group are related to raw CB. To identify the original source of metals in the surrounding area, two large subgroups were determined: the first group contained only the variables $\mathrm{Al}, \mathrm{Fe}$, and $\mathrm{Zn}$ and the 
second group included $\mathrm{Pb}$ and other metals (Fig. 4(b)). In this case, the first group is related to emissions from the CB feeding process. Unfortunately, the probable sources of the second group were difficult to identify because the metal contents in this group did not show significant variances. The characteristics of metal-containing particles are affected by their emission sources. Therefore, the contributions of metallic contents in different particle sizes could be used as a marker of probable exhaust sources.

Fig. 5(a) and (b) respectively illustrate the total relative contents of metals in particles sampled at the CB feeding and surrounding areas. Fig. 5(a) shows that the $\mathrm{Al}, \mathrm{Fe}$, and $\mathrm{Zn}$ metal contents in coarse particles (49.1-62.0\%) contributed the most to the total PM content, followed by those in $\mathrm{PM}_{0.1-1.8}$ (23.2$36.8 \%)$ and UFPs (14.5-32.5\%). Other metal contents were distributed mainly in UFPs (46.3-67.7\%), thus demonstrating that UFPs pose greater adverse health effects than larger particles per unit mass in the CB feeding area. Since no other raw materials were fed in the workshop, the metal contents of the collected particles clearly represent the characteristics of raw $\mathrm{CB}$ nanoparticles.

Fig. 5(b) shows that the mean percentage contributions of $\mathrm{Al}$, $\mathrm{Fe}, \mathrm{Zn}, \mathrm{Cu}$, and $\mathrm{Co}$ in the coarse particles ranged from $49.1 \%$ to $69.1 \%$, thus indicating that the content contributions of $\mathrm{Al}, \mathrm{Fe}$, and $\mathrm{Zn}$ to coarse particles were affected by CB feeding area emissions. Although $\mathrm{Cu}$ and $\mathrm{Co}$ may be emitted by crustal elements, the results of the present study suggest that most of the $\mathrm{Cu}$ in the coarse particles comes from the road dust of the surrounding area. Road dust contains dust from the brakes and tires of vehicles. The average mass median diameters of brake dust range from $0.62 \mu \mathrm{m}$ to $2.49 \mu \mathrm{m} .^{32}$ The $\mathrm{Cu}$ content of brake dust has been recognized to be a significant pollutant, ${ }^{24,33}$ contributing $47 \%$ of the total $\mathrm{Cu}$ load in urban runoff. ${ }^{24,34} \mathrm{Cu}$ is used to control heat transport. ${ }^{35}$ A large amount of $\mathrm{Mn}$, which probably comes from the fumes produced during manual metal arc welding in the tire plant, was observed in $\mathrm{PM}_{0.1-1.8}(67.8 \%)$. The diameters of most of the particles found in emitted welding fumes range from $0.56 \mu \mathrm{m}$ to $0.1 \mu \mathrm{m} .{ }^{36}$ Besides $\mathrm{Fe}, \mathrm{Cr}$, and $\mathrm{Ni}$, welding fumes contain high concentrations of $\mathrm{Mn}$ and $\mathrm{Zn} .^{37}$ Some combinations of multiple elements have been found to be specific to particular sources or process, thereby enabling these particle classes to be used as markers. ${ }^{38}$ However, most of the toxic metals found in $\mathrm{PM}_{0.1-1.8}$ were observed in the surrounding atmosphere of the tire manufacturing plant.

\section{Deposition fluxes in the respiratory system and health-risk assessment}

Fig. 6 presents the deposition fluxes of the means and 95\% confidence intervals (CI) of total particle-bound heavy metals in the human respiratory tracts of workers, adults, and children. The mean total deposition fluxes of atmospheric particle-bound heavy metals in the HA, TB, and AR were 68081.5 (CI: 36 817.599 345.5), 2268.0 (CI: 1307.4-3228.5), and 4374.1 (CI: 2788.95959.4) ng per day, respectively. The total deposition fluxes $(\mathrm{HA}+\mathrm{TB}+\mathrm{AR})$ of atmospheric particle-bound heavy metals in adults and children were 13537.7 and 6768.9 ng per day, respectively. Mean values following the sequence $\mathrm{HA}>\mathrm{AR}>\mathrm{TB}$ demonstrated similar trends among workers, adults, and children. The ratios of total mean deposition fluxes in workers/ adults, workers/children, and adults/children were approximately 5.5, 11.0, and 2.0, respectively. Fig. 6 shows the differences in the total deposition fluxes of particle-bound heavy metals among workers, adults, and children, which were determined using Kruskal-Wallis test. As the results showed very strong evidence of a difference $(p<0.001)$ between the mean ranks of at least one pair of groups, the Dunn's pairwise tests were carried out for three pairs of groups. Differences were observed between workers-adults and workers-children $(p<$ 0.05 and $p<0.001$, respectively, adjusted using the Bonferroni correction). This study compared the mean total deposition fluxes of adults and children with those in an e-waste recycling zone, ${ }^{18}$ and the total deposition fluxes of metals in adults and children near the tire plant were about 0.4 times lower than those in the recycling zone. This result reveals that the enclosed plant control management style implemented in the CB feeding area was is better than open treatment method practiced in the e-waste recycling zone. Thus, enclosed plant control management could reduce the adverse health effects of tire manufacturing on residents living near the tire plant.
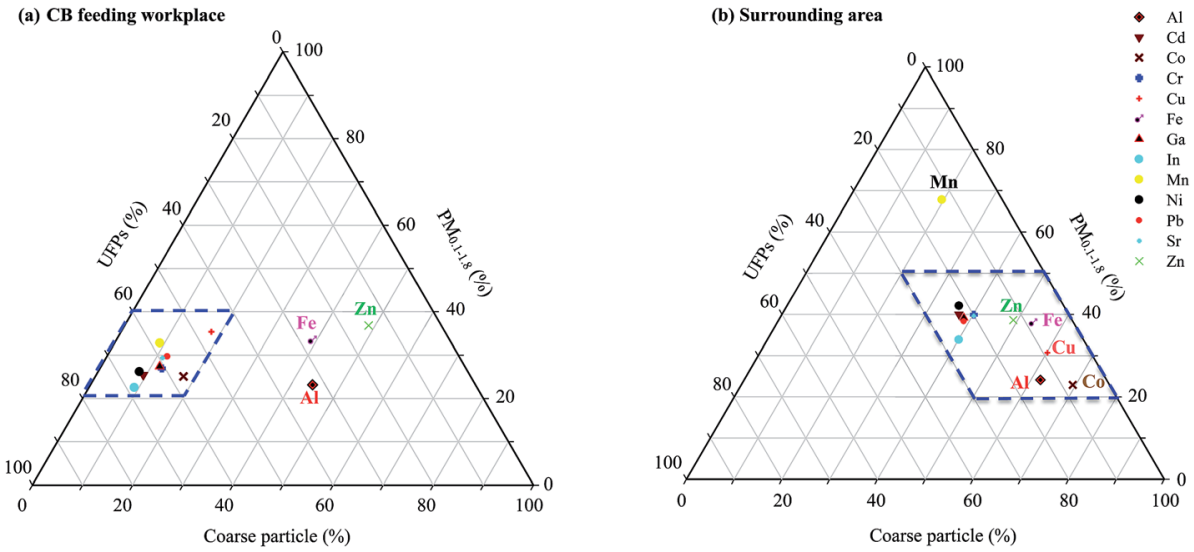

Fig. 5 Triangular diagrams showing heavy metal speciation in different particle sizes: (a) carbon black feeding and (b) surrounding areas. 


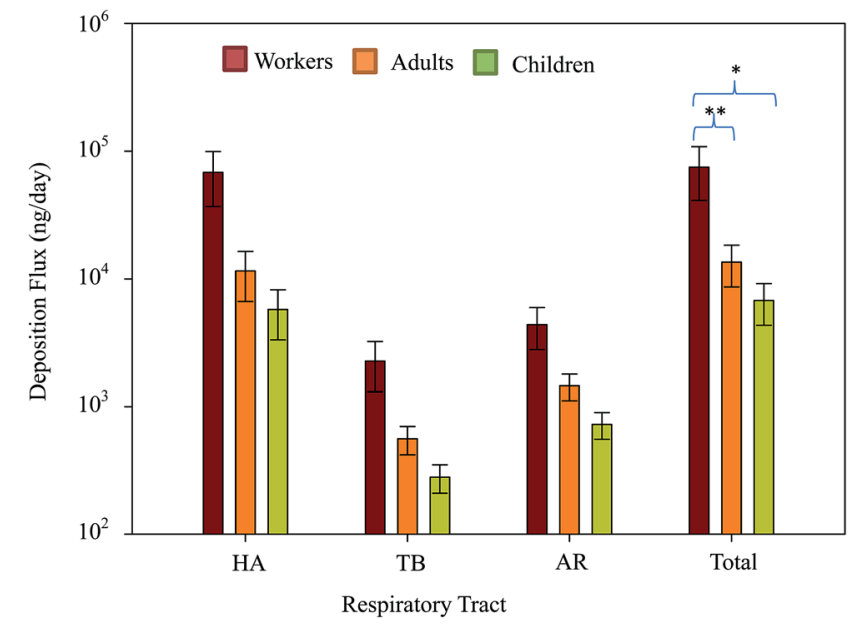

Fig. 6 Deposition fluxes and 95\% confidence intervals of total particle-bound heavy metals in the human respiratory tracts of workers, adults, and children. $p<0.05$ and $* * p<0.01$ compared to the workers.

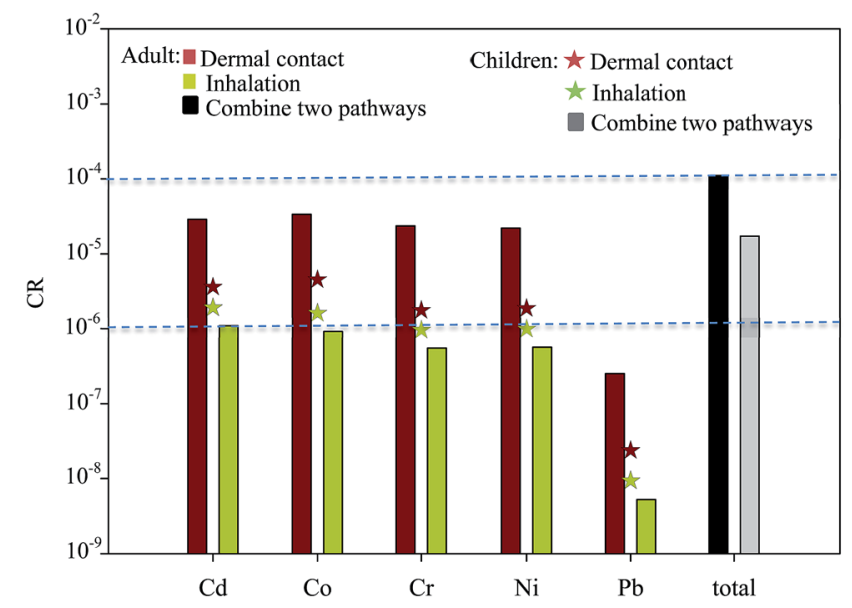

Fig. 7 Cancer risk assessment of carcinogenic metals via dermal contact and inhalation.

To assess the health risk posed by toxic metals in the ambient air of surrounding areas to residents (both adults and children), the carcinogenic effects of toxic metals via the major exposure pathways of inhalation and dermal contact were estimated. The CRs of toxic metals in the total PM presented by these two exposure pathways are shown in Fig. 7. The dermal contact CR of the ambient air of the surrounding area was highest for Co $\left(3.3 \times 10^{-5}\right)$, followed by Cd $\left(2.9 \times 10^{-5}\right)$ and $\mathrm{Cr}$ $\left(2.3 \times 10^{-5}\right)$ for adults. The mean dermal contact CR of five elements for adults was approximately 10 times higher than that for children. Means inhalation of the CR presented by $\mathrm{Cd}$, $\mathrm{Co}, \mathrm{Cr}, \mathrm{Ni}$, and $\mathrm{Pb}$ as determined by the ICRP model. Among the CRs determined, the CR presented by Cd inhalation of the total PM for adults and children was the highest, followed by those of $\mathrm{Co}$ and Ni. Because the inhalation rates of the total PM in the respiratory tract were not $100 \%$, the CR presented by dermal contact was higher than that presented by inhalation. These
Table 4 Mean deposited fractions of total particle-bound metals in the human respiratory tract

\begin{tabular}{lccc}
\hline Site & HA & TB & AR \\
\hline Surrounding area & $59.02 \pm 35.58$ & $2.68 \pm 0.32$ & $7.02 \pm 0.49$ \\
Workplace & $73.22 \pm 2.59$ & $2.49 \pm 0.29$ & $5.19 \pm 1.13$ \\
\hline
\end{tabular}

results are consistent with those of other studies. ${ }^{39-43}$ The CRs presented by inhalation for children were higher than those for adults. The CR of Cd inhalation for adults and children and that of Co inhalation for children exceeded the $10^{-6}$ benchmark level. The integrated risks presented by five elements via two exposure pathways to adults and children were $1.1 \times 10^{-4}$ and $1.7 \times 10^{-5}$, respectively, thus demonstrating the high cumulative CR posed by these metals to local residents (both adults and children).

Toxic metals have attracted growing attention in urban cities near industrial plants because of the effects of PM on public health. The daily intakes of toxic constituents via ingestion, dermal contact, and inhalation have been calculated, and, among the three pathways, the respiratory system was found to provide the easiest exposure route. The adverse effects of inhaled toxic metals can be widely found in previous publications that used $75 \%$ penetration levels to assess fractions containing high concentrations of total particle-bound contaminants penetrating the lungs. ${ }^{\mathbf{1 6 4 4 - 4 6}}$ In this study, the majority $(59.02 \% \pm 35.58 \%)$ of the deposition amounts among residents was observed in the HA; only $2.68 \% \pm 0.32 \%$ and $7.02 \% \pm 0.49 \%$ of the total particles were deposited in the TB and AR, respectively (Table 4). The mean total portions deposited in the respiratory tract of residents and workers were $88.24 \%$ and $82.56 \%$, respectively. A similar trend was observed in the e-waste recycling zone. The results of the present study suggest that the inhalable fraction deposited into the AR was much lower than the empirical value of $75 \%$. Therefore, assessments based on total contaminants could show overestimated exposure risks.

The ICRP model used in the current study presents a number of limitations, such as underestimation of the deposition of ultrafine particles in the lower human respiratory tract ${ }^{47}$ and ignorance of the presence and commensurate effects of naturally occurring structural elements of the lungs (e.g., cartilaginous rings, carinal ridges), which have been demonstrated to affect the motion of inhaled air. ${ }^{48}$ While these limitations could affect the assessment of CRs, the results still provide important insights into novel protection strategies associated with exposure to particle-bound metals.

\section{Conclusions}

This study was conducted to investigate the effects on human health and size distributions of CB particles in a tire manufacturing plant. In the surrounding area, particles with the highest mass by size were $\mathrm{PM}_{0.56-1.0}$, and the MMD of the total airborne mass was mainly incorporated in submicron 
particles $\left(\mathrm{PM}_{1}\right)$. The most abundant elements $(\mathrm{Fe}, \mathrm{Al}$, and $\mathrm{Zn})$ in all fractions of the surrounding area were similar to those of the CB feeding area. The MMDs of the total metal concentration in the surrounding and CB feeding areas were $1.21 \pm 0.41$ and 2.05 $\pm 0.79 \mu \mathrm{m}$, respectively. Cluster analysis revealed that the CB feeding process is the main emitter of metals in the surrounding area. The mean values of total particle-bound heavy metals in the human respiratory tract following the sequence $\mathrm{HA}>\mathrm{AR}>\mathrm{TB}$ demonstrated similar trends among workers and residents. CR values of inhalation for children were higher than those for adults. The inhalation CRs of $\mathrm{Cd}$ for adults and children and Co for children exceeded the $10^{-6}$ benchmark level. Although the existing plant control management of tire manufacturing reduced the adverse health effects of $\mathrm{CB}$ on residents living near the tire plant, this study suggests that $\mathrm{CB}$ emission can be effectively controlled by applying negative pressure using local exhaust ventilations. Then, the $\mathrm{CB}$ particles can be reused by collecting them using a bag house or other equipment. The results provide new information regarding the emissions of $\mathrm{CB}$ manufacturing plants.

\section{Conflicts of interest}

There are no conflicts of interest to declare.

\section{Acknowledgements}

The author would like to thank the Ministry of Science and Technology (MOST) in Taiwan for the financial support under the Grant No. MOST 104-2221-E-166-001.

\section{References}

1 M. J. Wang, C. A. Gray, S. A. Reznek, K. Mahmud and Y. Kutsovsky, Kirk-Othmer Encyclopedia of Chemical Technology, 2003.

2 A. Y. Watson and P. A. Valberg, AIHAJ, 2001, 62, 218-228.

3 C. M. Long, M. A. Nascarella and P. A. Valberg, Environ. Pollut., 2013, 181, 271-286.

4 R. Baan, K. Straif, Y. Grosse, B. Secretan, F. El Ghissassi and V. Cogliano, Lancet Oncol., 2006, 7, 295.

5 IARC, IARC Monographs on the Evaluation of Carcinogenic Risks to Humans, in Carbon Black, Titanium Dioxide, and Talc, International Agency for Research on Cancer (IARC), World Health Organization (WHO), Lyon, France, 2010, vol. 93.

6 R. J. McCunney, P. Morfeld, L. Levy and H. Muranko, Environ. Health Perspect., 2011, 119, a332.

7 P.-J. Tsai, H.-Y. Shieh, W.-J. Lee and S.-O. Lai, J. Hazard. Mater., 2002, 91, 25-42.

8 N. Li, C. Sioutas, A. Cho, D. Schmitz, C. Misra, J. Sempf, M. Wang, T. Oberley, J. Froines and A. Nel, Environ. Health Perspect., 2003, 111, 455-460.

9 Y. Cao, M. Roursgaard, P. H. Danielsen, P. Moller and S. Loft, PLoS One, 2014, 9, e106711.
10 J. Yan, C.-C. Huang, S.-C. C. Lung, W.-C. Wang, G. Suo, Y.-J. Lin, C.-H. Lai and C.-H. Lin, Environ. Sci.: Nano, 2017, 4, 1525-1533.

11 J. Yan, C. Lai, S. Lung, W. Wang, C. Huang, G. Chen, G. Suo, C. Choug and C. Lin, J. Hazard. Mater., 2017, 338, 66.

12 H. Collyer, Carbon Black-Environmental Health, Unpublished report submitted to NIOSH, Carbon Black Industry Committee for Environmental Health, 1975, p. 7.

$13 \mathrm{~J} . \mathrm{Hu}, \mathrm{F} . \mathrm{Wu}, \mathrm{S} . \mathrm{Wu}, \mathrm{Z}$. Cao, X. Lin and M. H. Wong, Chemosphere, 2013, 91, 455-461.

14 T. Joseph, B. Dubey and E. A. McBean, Sci. Total Environ., 2015, 527, 552-560.

15 Q. Pasha, S. A. Malik, N. Shaheen and M. H. Shah, Clin. Chim. Acta, 2010, 411, 531-539.

16 K.-Y. Chuang, C.-H. Lai, Y.-P. Peng and T.-Y. Yen, Environ. Sci. Pollut. Res., 2015, 22, 19451-19460.

17 H. Smith, ICRP Publication 66, 1994.

18 C.-L. Huang, L.-J. Bao, P. Luo, Z.-Y. Wang, S.-M. Li and E. Y. Zeng, J. Hazard. Mater., 2016, 317, 449-456.

19 USEPA, Risk assessment guidance for Superfund: volume IIIpart A, process for conducting probabilistic risk assessment, 2001.

20 USEPA, Human Health Evaluation Manual (Part A). Risk Assessment Guidance for Superfund Volume I, 1989.

21 R. Goyer, M. Golub, H. Choudhury, M. Hughes, E. Kenyon and M. Stifelman, Issue paper on the human health effects of metals, US Environmental Protection Agency, Risk Assessment Forum, 2004.

22 USEPA, Supplemental guidance for assessing susceptibility from early-life exposure to carcinogens, Risk Assessment Forum, 2005.

23 USEPA, Risk Assessment Guidance for Superfund Volume I: Human Health Evaluation Manual (Part E, Supplemental Guidance for Dermal Risk Assessment), 2004.

24 K. Adachi and Y. Tainosho, Environ. Int., 2004, 30, 10091017.

25 A. Liati, P. D. Eggenschwiler, E. M. Gubler, D. Schreiber and M. Aguirre, Atmos. Environ., 2012, 49, 391-402.

26 M. Patel, C. L. A. Ricardo, P. Scardi and P. B. Aswath, Tribol. Int., 2012, 52, 29-39.

27 J. Kukutschová, P. Moravec, V. Tomášek, V. Matějka, J. Smolík, J. Schwarz, J. Seidlerová, K. Šafářová and P. Filip, Environ. Pollut., 2011, 159, 998-1006.

28 K. Adachi and P. R. Buseck, Environ. Sci. Technol., 2010, 44, 2299-2304.

29 X. Lu, L. Wang, L. Y. Li, K. Lei, L. Huang and D. Kang, J. Hazard. Mater., 2010, 173, 744-749.

30 S. A. Doabi, M. Afyuni and M. Karami, J. Geochem. Explor., 2017, 180, 61-70.

31 Ş. Tokalıoğlu and Ş. Kartal, Atmos. Environ., 2006, 40, 27972805.

32 B. D. Garg, S. H. Cadle, P. A. Mulawa, P. J. Groblicki, C. Laroo and G. A. Parr, Environ. Sci. Technol., 2000, 34, 4463-4469.

33 J. Sternbeck, Å. Sjödin and K. Andréasson, Atmos. Environ., 2002, 36, 4735-4744.

34 A. P. Davis, M. Shokouhian and S. Ni, Chemosphere, 2001, 44, 997-1009. 
35 P. J. Blau, Compositions, functions, and testing of friction brake materials and their additives, Oak Ridge National Lab., TN (US), 2001.

36 S. S. Leonard, B. T. Chen, S. G. Stone, D. Schwegler-Berry, A. J. Kenyon, D. Frazer and J. M. Antonini, Part. Fibre Toxicol., 2010, 7, 32.

37 M. Stanislawska, T. Halatek, M. Cieslak, I. Kaminska, R. Kuras, B. Janasik and W. Wasowicz, Microchem. J., 2017, 135, 1-9.

38 B. R. Bzdek, M. R. Pennington and M. V. Johnston, J. Aerosol Sci., 2012, 52, 109-120.

39 H. Xu, S. Han, X. Bi, Z. Zhao, L. Zhang, W. Yang, M. Zhang, J. Chen, J. Wu, Y. Zhang and Y. Feng, J. Hazard. Mater., 2016, 304, 93-102.

40 L. Ferreira-Baptista and E. De Miguel, Atmos. Environ., 2005, 39, 4501-4512.
41 Q. Yang, H. Chen and B. Li, Arch. Environ. Contam. Toxicol., 2015, 68, 20-30.

42 P. B. Kurt-Karakus, Environ. Int., 2012, 50, 47-55.

$43 \mathrm{X}$. Hu, Y. Zhang, J. Luo, T. Wang, H. Lian and Z. Ding, Environ. Pollut., 2011, 159, 1215-1221.

44 J. Nouwen, C. Cornelis, R. De Fre, M. Wevers, P. Viaene, C. Mensink, J. Patyn, L. Verschaeve, R. Hooghe and A. Maes, Chemosphere, 2001, 43, 909-923.

45 S. Harrad, R. Wijesekera, S. Hunter, C. Halliwell and R. Baker, Environ. Sci. Technol., 2004, 38, 2345-2350.

46 T.-S. Shih, W.-J. Lee, M. Shih, Y.-C. Chen, S.-L. Huang, L.-C. Wang, G.-P. Chang-Chien and P.-J. Tsai, Environ. Int., 2008, 34, 102-107.

47 M. Lippmann, Comprehensive Physiology, 1977.

48 Y. Lyu, K. Zhang, F. Chai, T. Cheng, Q. Yang, Z. Zheng and X. Li, Environ. Pollut., 2017, 224, 559-571. 